Robertson R, Robertson A, Jepson R \& Maxwell M (2012) Walking for depression or depressive symptoms: a systematic review and meta-analysis, Mental Health and Physical Activity, 5 (1), pp. 66-75.

This is the peer reviewed version of this article

NOTICE: this is the author's version of a work that was accepted for publication in Mental Health and Physical Activity. Changes resulting from the publishing process, such as peer review, editing, corrections, structural formatting, and other quality control mechanisms may not be reflected in this document. Changes may have been made to this work since it was submitted for publication. A definitive version was subsequently published in Mental Health and Physical Activity, [VOL 5, ISSUE 1, (2012)] DOI 10.1016/j.mhpa.2012.03.002 


\title{
WALKING FOR DEPRESSION
}

\begin{abstract}
Problem: Depression is a common disorder worldwide. Most patients are treated within primary care and antidepressant treatment is not recommended for people with mild depression. Physical activity has been shown to alleviate depression but it is not known whether the less vigorous activity of walking - a potentially widely acceptable and safe intervention - confers such benefit. Method: Eleven databases were systematically searched for randomised controlled trials of walking as a treatment intervention for depression, from database inception until January 2012. Meta-analyses were carried out on all trials eligible for inclusion and on sub-groups of outdoor, indoor and group walking.

Results: Of the 14,672 articles retrieved, eight trials met the inclusion criteria. The pooled standardised mean difference (effect size) was $-0.86[-1.12,-0.61]$ showing that walking has a statistically significant, large effect on symptoms of depression. However, there was considerable heterogeneity amongst the interventions and research populations and it is uncertain whether the results can be generalised to specific populations such as primary care patients.

Conclusions: Walking has a statistically significant, large effect on the symptoms of depression in some populations, but the current evidence base from randomised, controlled trials is limited. Thus, while walking is a promising treatment for depression or depressive symptoms with few, if any, contraindications, further investigations to establish the frequency, intensity, duration and type(s) of effective walking interventions particularly in primary care populations would be beneficial for providing further recommendations to clinical practitioners.
\end{abstract}

Keywords: depression, physical activity, walking, systematic review, meta-analysis 


\section{Introduction}

Depression is an illness or mood disorder with a variety of symptoms, the most defining being an inexplicable, enduring feeling of sadness (loss of positive affect). It is categorised as mild, moderate or severe depending upon the number and severity of the symptoms (WHO, 2010). It is a common mental health problem, estimated in 2000 to be the fourth leading cause of disease burden worldwide (WHO, 2003; Ustun, Ayuso-Mateos, Chatterji, Mathers, \& Murray, 2004). It causes a level of morbidity comparable to or worse than other common chronic diseases such as asthma and diabetes (Moussavi et al., 2007). In the UK over $75 \%$ of patients with depression are treated solely within primary care (NICE, 2010) where prevalence is estimated at 7\% (Ostler et al., 2001).

Depression is commonly treated with anti-depressant medications, psychological therapies or a combination of both. The efficacy of anti-depressants for mild depression has been questioned (Moncrieff \& Kirsch, 2005) and they are not recommended to be used routinely by people with persistent sub-threshold depressive symptoms or mild depression in the first instance (NICE, 2010). There is also a range of side effects (Demyttenaere, 2003), many people do not like taking medicines (Maxwell, 2005; Givens et al., 2006; Townsend, Hunt, \& Wyke, 2003; Kessing, Vibe Hansen, Demyttenaere, \& Bech, 2005) and early drop-out rates in clinical trials vary from $12 \%$ to $40 \%$ (Cipriani et al., 2009; Kirsch et al., 2008). Psychological therapies are resource intensive, and may require cognitive capabilities a person with depression cannot attain. Consequently, for many years there has been interest in physical activity (and other alternative therapies) as a stand-alone or adjunctive treatment for depression (Scottish Intercollegiate Guidelines Network, 2010). Several systematic reviews (Mead et al., 2009; Mead, Morley, Greig, McMurdo, \& Lawlor, 2008; Lawlor \& Hopker, 2001; Sjosten \& Kivela, 2006) and a review of reviews (Daley, 2008) have concluded that exercise appeared to improve symptoms of depression, but that the methodological quality of available trials was often too poor to reach a robust conclusion. A further meta-analysis by Stathopoulou (Stathopoulou, Powers, Berry, Smits, \& Otto, 2006, p. 188) concluded that "exercise can be a powerful intervention for clinical 
depression", and another systematic review of the effect of exercise in clinically depressed adults by Krogh and colleagues found that there was a short-term positive effect of exercise on depression but no positive long-term effect (Krogh, Nordentoft, Sterne, \& Lawlor, 2011). For patients with persistent sub-threshold or mild to moderate depression, current UK NICE guidelines (NICE, 2010) recommend structured physical activity programmes, individual guided self-help based on cognitive behavior therapy (CBT) principles and/or computerised CBT as treatment choices. It is recommended that the physical activity programmes are group based and led by a trained practitioner thrice weekly for 45 minutes to one hour for a period of 10 to 14 weeks.

Walking is a form of physical activity that has the potential to alleviate depression. When taken outdoors, the addition of being able to observe or experience an attractive natural environment has been shown to have a restorative effect, decreasing levels of stress, (Ulrich, 1983; Kaplan \& Kaplan, 1989; Hartig, Mang \& Evans, 1991) which could contribute to reducing symptoms of depression. Walking has the advantages of being easily undertaken by most people, incurring little or no financial cost, having minimal risk of adverse effects and being relatively easy to incorporate into daily living. Consequently, walking is promoted in many developed countries throughout the world (Paths for All, 2011; 10,000 Steps Project, 2011; Centers for Disease Control and Prevention, 2011; Health Canada, 2011; International Longevity CenterUSA, 2011; Natural England, 2011; NHS Choices Information, 2011; Welsh Assembly Government, 2011) to counteract increasingly sedentary lifestyles and the health consequences of physical inactivity. While existing systematic literature reviews with meta-analyses (Mead et al., 2009; Lawlor et al., 2001; Krogh et al., 2011) have found positive, but not conclusive evidence, to support exercise as an intervention for depression, to our knowledge no review to date has evaluated the effectiveness of specific types of physical activity.

A variety of mechanisms to explain why physical activity might reduce depressive symptoms has been suggested (Craft \& Perna, 2004). These include biochemical (including endorphin and monoamine hypotheses), physiological (thermogenic, cardiovascular fitness, and 
sleep improvement hypotheses) and psychological and psychosocial hypotheses such as distraction, self-efficacy and enhancement of self-esteem (Sonstroem \& Morgan, 1989) or increasing positive affect (White, Kendrick, \& Yardley, 2009; Clark \& Watson, 1991). Whichever mechanism or combination of mechanisms are responsible for physical activity reducing depressive symptoms, there is uncertainty regarding the optimum dose (duration and frequency of sessions, length of programme) and intensity and which specific type(s) of physical activity benefit depression (Mead et al., 2008). It is not known whether walking is a form of physical activity that is sufficiently vigorous to stimulate sufficient biochemical or physiological changes to be an effective treatment for depression and whether walking interventions contribute to or diminish the overall effect sizes reported.

If the available evidence were able to demonstrate that walking is an effective physical activity for the treatment of depression, this knowledge could inform current recommendations and give health professionals greater confidence in the benefits of walking when advising patients who are depressed. We therefore carried out a systematic review of the existing literature to examine the effectiveness of walking as an intervention for alleviating depression in adults, and performed a meta-analysis on relevant data. Further, we considered walking outdoors, walking indoors and walking in a group.

\section{Method}

\section{Literature search}

The following key words were translated into the appropriate search syntax for the databases listed below:

(i) depression, depressive disorder, dysthymia, affective disorder, mood

(ii) walk, walking, ambulatory, physical activity

(iii) randomised controlled trial

Searches were conducted with no language restrictions in electronic databases from the date the database was first published until August 2009, and updated in January 2012. The databases 
searched were: MEDLINE, AMED, EMBASE, PsycInfo, CINAHL, Physical Education Index, PsycArticles, Web of Science, SportDiscus, IBBS, and the Cochrane Central Register of Controlled Trials.

The Internet, the reference lists of relevant reviews of trials and of the trials themselves, and citations of the trials, were also searched. The investigators of past and ongoing trials were contacted to determine if any further data were available.

\section{Trial selection}

Trials were considered eligible if they reported a randomised, controlled trial, with adult (18 years or more) participants experiencing depression (as defined by the trial authors), who were treated with a walking intervention in any setting. We made an a priori decision to include all categories of depression (including post partum depression) with the exception of bipolar disorder because we did not wish the results to be contaminated by the natural progression from depression to mania in this disorder. Also excluded were trials with participants suffering mental health disorders other than depressive disorders and trials with participants selected on the basis of medical conditions (e.g. cancer). Eligible interventions were any structured or semi-structured walking treatment, indoors or outdoors, either as a single treatment or in combination with other treatment for depression. We excluded trials where some in the intervention group carried out an activity other than walking, such as higher-intensity jogging, and trials where participants could carry out other activities as well as walking, for example, stationary cycling and weight training; in these trials, data relating specifically to walking were not reported. We included trials where, in addition to the main intervention of walking, participants did warm up, cool down or other short periods of stretching as we believed these minor variations to a walking intervention were unlikely to influence any effect of walking on depression.

\section{Data extraction}

Titles of all the articles found using the search strategy described above were screened (half each by RR and AR) and papers that were clearly ineligible were discarded. The abstracts of the remaining trials were assessed and trials clearly not meeting the inclusion criteria discarded. Two 
review authors (RR and AR) accessed full copies of the remaining papers and independently assessed whether the trials met the inclusion criteria. Any differences of opinion were resolved by discussion among the review team. If necessary and possible, further clarification was sought from original authors. Data on the location of the trial, the methods - including trial quality, the participants, the nature of the intervention and control activities - and data relating to the trial outcomes were extracted (by either RR and AR and checked by the other) using a structured format. Where outcome data were not presented in the primary trials as required for this review, they were obtained from an earlier review by Mead et al. (2008), acquired from authors or calculated from the available data as described in the Cochrane Handbook (The Cochrane Collaboration, 2011a).

\section{Trial Quality}

Information on the use of allocation concealment during randomisation, intention to treat analysis, sample size calculations and blinding of the assessors in the included trials was also extracted.

\section{Comparisons}

Results were analysed for all trials which compared a walking intervention with a control of no treatment, usual care or a treatment (such as cognitive behaviour therapy) that was also included as part of the intervention. They were also analysed in subgroups of the trials for outdoor walking, indoor walking and walking in a group.

\section{Statistical analysis}

Several different psychometric instruments are commonly used as outcome measures of depression and to be able to undertake a meta-analysis the standardised mean difference was calculated for each trial using RevMan5 software (Review Manager, 2011). Both random effects and fixed effects models were employed to calculate the pooled effect sizes and the model which gave the most conservative result was used (The Cochrane Collaboration, 2011a).

\section{Results}


A total of 14,672 titles was retrieved, the abstracts of 364 were considered and the full texts of 103 trials were obtained (Figure 1). From these, seven separate trials fully met the inclusion criteria (Armstrong \& Edwards, 2003; Armstrong \& Edwards, 2004; Bonnet, 2005; Knubben et al., 2007; McNeil, LeBlanc \& Joyner, 1991; Mota-Pereira et al., 2011; Nguyen, 2008). We decided to include one further trial (Gusi, Reyes, Gonzalez-Guerrero, Herrera \& Garcia, 2008), which recruited participants with a high body mass index in addition to patients who were depressed. This was included because the study had a large sample size thereby including a significant number of people with depression and had been conducted within a primary care setting. In addition, there is an association between high body mass index and depression (de Wit, van Straten, van Herten, Penninx, \& Cuijpers, 2009). Sensitivity analysis was carried out to determine the impact of this decision. These eight studies provided a total of 341 participants randomised to treatment or control. Table 1 provides details of these trials included in the review, with information on the participants, the countries, the interventions and quality criteria. Information about the trials that were excluded is available from the first author on request.

\section{Participants}

In the included trials there was a variety of participant groups (postpartum women, students, women only and people from different age groups $(50+, 60+, 20-70$ years and elderly with mean age 72.5 years)); from a variety of settings (community or university campus settings, primary care, and inpatient or outpatient hospital care), with a range of severity of depression which was diagnosed in different ways (see Tables 1 and 2). One trial (Gusi et al. 2008) included participants who were overweight (64\%) as well as those with a diagnosis of depression. We were unable to isolate the participants who had been recruited because of their high body mass index and they are included in the analysis.

The number of participants in each trial was generally quite small, ranging from 11 to 127 and with an average of 43 . 
Walking was the primary intervention in all trials, but many variations existed. The main description of each intervention is given in Table 1 with further details in Table 3. In four trials (Armstrong \& Edwards, 2003; Armstrong \& Edwards, 2004; Gusi et al. 2008; Nguyen, 2008) participants had a warming up or cooling down period or other time when they did stretching exercises.

Three trials involved outdoor walking (Armstrong \& Edwards, 2003; Armstrong \& Edwards, 2004; Gusi et al. 2008), three indoor walking (Bonnet, 2005; Knubben et al., 2007; Nguyen, 2008) (with two using treadmills (Bonnet, 2005; Knubben et al., 2007)) and two involved both indoor and outdoor walking (McNeil et al., 1991; Mota-Pereira et al., 2011). In six trials (Armstrong \& Edwards, 2003; Armstrong \& Edwards, 2004; Bonnet, 2005; Gusi et al. 2008; Knubben et al., 2007; Nguyen, 2008) the walking was led or supervised all the time; in one trial (McNeil et al., 1991) two of the three weekly walks were led, and in the final trial (MotaPereira et al., 2011) one of the five weekly walks was supervised. In three trials (Armstrong \& Edwards, 2003; Armstrong \& Edwards, 2004; Gusi et al. 2008) participants walked as a group, although in one of these (Armstrong \& Edwards, 2004) they undertook one of the three weekly walks individually.

In all but one trial (Nguyen, 2008), a specific intensity of exercise was aimed for (Table 3). In four trials (Armstrong \& Edwards, 2003; Armstrong \& Edwards, 2004; Bonnet, 2005; Knubben et al., 2007) this was based on heart rate, in one (Mota-Pereira et al., 2011) it was based on speed, and in two others the walk leaders aimed at achieving vigorous (McNeil et al., 1991) or brisk (Gusi et al. 2008) walking.

The lengths of the interventions varied from an average of 3.5 sessions over 6.2 days to six months and the length of individual sessions from 20 - 50 minutes. In two of the trials (Knubben et al., 2007; Nguyen, 2008) walking sessions took place daily, in one (Mota-Pereira et al., 2011) participants were asked to walk on five days each week, in four (Armstrong \& Edwards, 2003; Armstrong \& Edwards, 2004; Gusi et al. 2008; McNeil et al., 1991) they aimed to walk on three days and in one (Bonnet, 2005) there were sessions on two days each week. 
Completion rates of intervention participants

All eight trials provided data on intervention completion rates (Table 4). Five had a completion rate equal to or greater than 90\% (Armstrong \& Edwards, 2003; Bonnet, 2005; Knubben et al., 2007; McNeil et al., 1991; Nguyen, 2008); Gusi et al. (2008) and Mota-Pereira et al. (2011) had completion rates of $86 \%$ and Armstrong \& Edwards (2004) of 75\%.

Participants in one trial (Mota-Pereira et al., 2011) wore accelerometers and data were downloaded weekly to check compliance to the walking regime. This might have influenced participants' levels of compliance. Reported methods of supporting, motivating participants to adhere to their walking regimes in each study are listed in Table 4.

\section{Controls}

The control groups varied in the activities in which they engaged (see Table 1). One trial (Knubben et al., 2007) used stretching and relaxation exercises as a control. Three had control groups with an element of social contact to control for the social aspects involved in the walking intervention; one (Armstrong \& Edwards, 2004) had a weekly support group (for new mums with depression), one (McNeil et al., 1991) had one of the research team making social visits and in Nguyen's (2008) trial the control group had sessions of talking (validation psychotherapy) with the researcher. One trial used a treatment (cognitive therapy) in the control group that was also used, in addition to walking, by the intervention group (Bonnet, 2005). In the remaining two trials participants received usual care (Armstrong \& Edwards, 2003; Gusi et al., 2008).

\section{Monitoring of fitness levels}

Four trials recorded fitness measurements for all participants at the beginning and end of the trial: two estimated maximal oxygen uptake $\left(\mathrm{VO}_{2} \max -\right.$ the maximum volume of oxygen that can be utilised in one minute during maximal or exhaustive exercise measured as millilitres of oxygen used in one minute per kilogram of body weight) (Armstrong \& Edwards, 2003; Armstrong \& Edwards, 2004), one (Mota-Pereira et al., 2011) measured heart rate and one (McNeil et al., 1991) the Cooper 12-minute walk test for aerobic capacity. Two trials recorded fitness measurements at the beginning and end of the trial for participants in the intervention arm 
only: Bonnet (2005) recorded resting heart rate and Knubben et al. (2007) $\mathrm{VO}_{2}$ max. Two trials (Gusi et al., 2008; Nguyen, 2008) did not measure participant fitness levels.

There were no apparent correlations between improvements in fitness and effect sizes (Table 5). In three trials (Armstrong \& Edwards, 2003; Armstrong \& Edwards, 2004; McNeil et al., 1991) there was a significant improvement in fitness in the intervention arm at the end of the trial, but only two of these (Armstrong \& Edwards, 2003; Armstrong \& Edwards, 2004) showed a significant effect of walking on depressive symptoms. McNeil et al. (1991), in addition, found at the end of the trial a significant improvement in fitness for the walking group compared to the social contact control group. In the two trials with no significant positive impact on fitness on the participants in the walking arm, one (Bonnet, 2005) had no significant effect on depressive symptoms and one (Knubben et al., 2007) did. Mota-Pereira et al. (2011) found a significant reduction in depression scores in the walking arm compared to the control, but no difference in fitness between the two groups.

\section{Quality of trials}

Table 1 provides details of quality indicators (allocation concealment, intention to treat analysis, sample size calculations and blinding of assessors) reported in the trial papers. The quality of the trials was mixed, with one trial (Knubben et al., 2007) reporting and meeting all four quality indicators, one (Armstrong \& Edwards, 2003) reporting three, two (Armstrong \& Edwards, 2004; Gusi et al.,2008) reporting two and four (Bonnet, 2005; McNeil et al., 1991; Mota-Pereira et al., 2011; Nguyen, 2008) reporting one. Visual inspection of the Forest plot (Figure 2) does not indicate any clear difference in effect sizes related to reported quality criteria, with the possible exception of a larger effect size in the one study (Nguyen, 2008) which did not report allocation concealment, intention to treat analysis or blinding.

\section{Outcome measures}

Several different outcome measures (Edinburgh Postnatal Depression Scale, Becks Depression Inventory, Becks Depression Inventory-1l, the Geriatric Depression Scale, the Hamilton Rating Scale for Depression and Bech-Rafaelsen Melancholy Scale) were used to 
detect any change in the levels of depression following the interventions in the included trials and these have been detailed in Table 2 .

\section{Pooled standardised mean difference (effect size)}

Data required for a meta-analysis were obtained for all eight trials and the results are shown in Figure 2. Using a fixed effects model, which calculated a more conservative figure than a random effects model (The Cochrane Collaboration, 2011b), the pooled standardised mean difference was $-0.86[-1.12,-0.61]$, which is statistically significant and generally considered to be a large effect size (The Cochrane Collaboration, 2011c). Statistical heterogeneity, the extent to which the differences in the effect sizes of individual studies varied compared to what would be expected by chance alone (The Cochrane Collaboration, 2011d), was measured using $\mathrm{I}^{2}$ and was high at $86 \%$.

Including only the four trials with the highest quality indicators in a sensitivity analysis reduced the effect size slightly to $-0.69[-0.99,-0.39]$, but it remained statistically significant.

The largest trial (Gusi et al., 2008) differed from the others because the majority (64\%) of participants was overweight and not necessarily depressed and the intervention included a larger range of non-walking exercises than the other trials. When the results of this trial were omitted from the meta-analysis the effect size became larger $(-1.01[-1.92,-0.11]$ using the more conservative result from a random effects model).

Sub group analysis

Four trials (Armstrong \& Edwards, 2003; Armstrong \& Edwards, 2004; Gusi et al., 2008; McNeil et al., 1991) involved walking outdoors and had a combined effect size of -0.60 [-0.91, 0.28]. The effect size of the three indoor trials (Bonnet, 2005; Knubben et al., 2007; Nguyen, 2008) was $-1.35[-1.84,-0.86]$.

In two trials (Armstrong \& Edwards, 2003; Gusi et al., 2008) the participants walked as a group activity and the effect size for these trials was $-0.60[-0.96,-0.24]$.

\section{Discussion}


Our meta-analysis of eight randomised, controlled trials found that walking was an effective intervention for depression having an effect size of $-0.86[-1.12,-0.61]$. This is comparable to the results of several recent systematic reviews and meta-analyses of physical activity (not restricted to walking) as a treatment for depression. The most recent of these reviews of which we are aware (Krogh et al., 2011) reported a lower effect size, with a pooled standardised mean difference of -0.40 (95\% CI, -0.66 to -0.14). Three others (Mead et al., 2009; Lawlor et al., 2001; Stathopoulou et al., 2006) had similar or larger effect sizes of -0.82 [-1.12, $0.51],-1.1[-1.5,-0.6]$ and $1.39[0.89,1.88]$ respectively. This suggests that walking has the potential to produce an effect in reducing symptoms of depression comparable to other forms of physical activity.

In our sub-group analyses, the trials of group walking were a sub-set of the outdoor walking trials, and both of these sub-group analyses had the same effect size $(-0.60)$. The combined effect size for the indoor walking trials was larger $(-1.35)$ but two of these three trials were of poorer quality, making it difficult to draw conclusions. Overall, the value of the subgroup analyses is limited by the small numbers of trials and participants, and further good quality walking trials are needed to determine whether there is added value, for example, to outdoor walking or walking in groups. The currently available evidence is inadequate to support the NICE (NICE 2010) recommendation for group exercise in cases where the exercise intervention is walking.

One of the strengths of this review was that it focused specifically on walking, thus a different set of trials has been reviewed than those in broader reviews of exercise as a treatment for depression. For example, the Mead Cochrane Review (Mead et al., 2008) comprised 23 trials comparing exercise with no treatment or control and two of these trials were eligible for the current review. The additional trials in our review included two with a population with postnatal depression, not included in the Mead review, and a further four, more recent trials.

In carrying out this systematic review the clinical and methodological heterogeneity of the trials and whether meta-analysis was an appropriate tool to use were carefully considered. 
Trials were only included if the reported outcome measures had a validated depression assessment, walking was the main intervention activity, all participants in the intervention arm walked, and their only other activities were gentle stretching and short exercises that were unlikely to influence any effect of walking on depression. Indeed, in one of the trials (Knubben et al., 2007) the control arm used such exercises. Despite this, the trials that met the inclusion criteria were clearly diverse in terms of the characteristics of participants, the outcome measures, and the intervention and control details. However, calculations of overall effect sizes have been carried out in previous systematic reviews that include different types of exercise (Lawlor et al., 2001; Mead et al., 2009; Krogh et al., 2011; Stathopoulou et al., 2006) and a meta-analysis was presented in this paper to provide a figure that was indicative of effectiveness and could be compared with the results of broader reviews of exercise interventions. Nonetheless, we acknowledge that, despite our decision to use the statistical model that gave the most conservative effect size, the large, positive effect size reported here should be treated with some caution.

The generalisability of our findings is limited by the specific populations of the eight trials. The individual standardised mean differences of six of these had significant positive effects on depression, one had a non-significant positive effect and one a significant negative effect (see Figure 2). The participants in the two trials without significant positive effects (Bonnet, 2005; McNeil et al., 1991) were not recruited in clinical or health care settings, the interventions lasted for six weeks and involved walking at a moderate or vigorous pace. Further research would be needed to discover if recruitment methods or other factors were important influences on these trials' negative findings. The participants in three of the six trials with positive effects (Knubben et al., 2007; Mota-Pereira, 2011; Nguyen, 2008) came from psychiatric hospital inpatient and outpatient populations and in two trials they comprised women with postpartum depression (Armstrong \& Edwards, 2003; Armstrong \& Edwards, 2004). The sixth, positive trial (Gusi et al., 2008) involved primary care patients with depression or high body mass index (conditions which are known to be associated with each other (de Wit et al., 2009) and given the large numbers of 
primary care patients with mild to moderate depression, (NICE, 2010; Ostler et al., 2001) further research is warranted to build on the results of this study.

While randomised, controlled trials offer the highest level of evidence for the effectiveness of treatments on specific diseases (Barton, 2000) they can be expensive and difficult to undertake in a methodologically rigorous manner (Hotopf, Lewis, \& Normand, 1997). This would certainly be true for the topic addressed in this paper as walking interventions can take diverse forms (as this review highlighted) and depression can vary from person to person and over time (Thornicroft \& Sartorius, 1993). In addition, it is not possible to blind trial participants and eradicate all forms of bias such as demand bias (when the participant acts to please the researcher rather than in their usual way) (Orne, 1962). Other levels of evidence have shown positive associations between walking and reducing depression. A summary of local health walk evaluations by the Countryside Agency (2005) found qualitative evidence that led walks had a "positive effect on walkers' mental health" (p28); two prospective cohort studies, one in older men with no past history of depression (Smith et al., 2010) and the other in older women (Heesch, Burton, \& Brown, 2011), found an inverse relationship between distances walked and future depressive symptoms; and a small, non-controlled trial of Nordic walking in patients with a history of depression (Suija et al., 2009) found an improvement in depressive symptoms. Such studies may add to the overall evidence base giving support to walking as a valuable treatment option. However, they would also need to be viewed within the context of their methodological limitations.

This review did not provide evidence that health professionals advising patients with depression to walk would have a positive effect on their depression, only that walking can be an effective treatment in research trial settings (Blumenthal \& Ong, 2009). How the effect sizes calculated in this and the broader reviews of exercise translate into clinical effectiveness is difficult to judge, but the positive result for walking interventions, which are also widely accessible and safe treatment options likely to deliver additional health benefits, offers strong support for further research into the clinical effectiveness of walking for patients with symptoms 
of depression, either as a sole intervention or as adjunctive therapy in both primary and secondary care settings. Ogilvie et al. (2007) found that general population interventions delivered at the level of individuals, households or groups were most effective at increasing walking and we hypothesise that health professionals, particularly in the primary care setting, are well placed to do this. For example, health professionals could 'prescribe' walking by referring the patient to an exercise referral scheme in which walking was an option and an intermediary exercise specialist supported patients in deciding their best method to increase physical activity; make direct referrals to a local walking group; or offer brief advice to the patient during a consultation. There are inherent challenges in motivating people with depression. While our review did not aim to address questions of intervention adherence, we observed low attrition rates in the walking trials overall, which compared favourably with reported attrition in pharmaceutical trials with participants with depression (Cipriani et al., 2009; Kirsch et al., 2008). The review trial that reported 100\% completion (Armstrong \& Edwards, 2003) had used a range of techniques, including taking a register and participants keeping diaries, which may have influenced participants' attendance, although there do not appear to be any clear correlations between motivational techniques and completion rates (see Table 4). Other authors have indicated that pedometers (Baker et al. 2008; Bravata et al. 2007) or exercise consultations (Lowther et al. 2002) could be helpful. Research questions relating to health promotion and treatment adherence in the context of walking interventions for depression remain to be answered.

The way in which exercise affects depression and depressive symptoms is still a source of speculation (Faulkner \& Carless, 2006). The lack of correlation between fitness improvement and reduction in depression symptoms found in this review concurs with other work (Brosse, Sheets, Lett, \& Blumenthal, 2002). The recent and growing evidence that improvements in fitness are determined more by genetic factors than levels of exercise (Bouchard et al., 2011; Timmons et al., 2010) could explain this, at least in part, suggesting that it is not improvements from baseline fitness but other aspects of exercise, such as its intensity, perceived intensity, duration or 
contextual factors, that need to be measured to help explain the mechanism(s) behind physical activity's positive effect on depression. However, the lack of obvious correlation between energy expenditure and effect sizes in the trials in this review and our overall finding that walking appears to reduce depression equally well as other more vigorous forms of exercise support arguments that the reduction in depressive symptoms is not directly related to energy expenditure either (King, Taylor \& Haskell, 1993; Rethorst, Wipfli \& Landers, 2009). In addition, while walking is often considered a more appropriate form of physical activity for older people, who may no longer be able to partake in vigorous activity, it appears from the evidence in this review to be beneficial to depressive symptoms in a wide range of ages. We would therefore hypothesise that mechanisms wholly dependent on energy expenditure are unlikely fully to explain how walking and other forms of exercise reduce depressive symptoms.

\section{Conclusions}

Walking has a statistically significant, large effect on the symptoms of depression in some populations but the current evidence base from randomised, controlled trials is limited.

Given that walking is potentially a widely accessible, safe and inexpensive treatment and in view of the high prevalence of depression in primary care patients, we recommend that future research should focus on evaluating walking interventions delivered in primary care settings. Investigations are needed to establish the frequency, intensity, duration and type(s) of walking interventions - i.e., walking individually or in a group, indoors or outdoors - that are most effective and practical for primary care patients with depression. Future research should also aim to clarify the optimum role for health care professionals in delivering walking as an intervention, and which factors reliably enhance primary care patients' adherence to walking programmes.

\section{Acknowledgements:}

We thank Marshall Dozier (Senior Liaison Librarian, College of Medicine, The University of Edinburgh) for assistance in developing the initial search strategy. 
We are grateful to authors (Armstrong, Da Costa, Daley, Foley, Hess-Homeier, Kerse, Mead, Mota-Pereira, Mutrie, and Nguyen) and Professors Grant Schofield and David French for personal communications and providing us with manuscripts, additional information and data. We also thank Marion Brady, Glasgow Caledonian University, for statistical advice, and reviewers for helpful comments on earlier versions of this manuscript. 


\section{References:}

References marked with an asterisk indicate studies included in the meta-analysis.

10, 000 Steps Project. (2011). 10,000 Steps. http://www.10000steps.org.au/ [Last accessed 24/05/2011]

*Armstrong, K. \& Edwards, H. (2003). The effects of exercise and social support on mothers reporting depressive symptoms: a pilot randomized controlled trial. International Journal of Mental Health Nursing, 12, 130-138. http://dx.doi.org/10.1046/j.14400979.2003.00229.x

*Armstrong, K. \& Edwards, H. (2004). The effectiveness of a pram-walking exercise programme in reducing depressive symptomatology for postnatal women. International Journal of Nursing Practice. vol.10, 100, 177-194. http://dx.doi.org/10.1111/j.1440-172X.2004.00478.x

Baker, G., Gray, S.R., Wright, A., Fitzsimons, C.F., Nimmo, M., Lowry, R., \& Mutrie, N. (2008). The effect of a pedometer-based community walking intervention "Walking for Wellbeing in the West" on physical activity levels and health outcomes: a 12-week randomized controlled trial. Int J Behav Nutr Phys Act., vol. 5, Barton, S. (2000). Which clinical studies provide the best evidence? The best RCT still trumps the best observational study. BMJ, 321, 255-256.

Blumenthal, J. A. \& Ong, L. (2009). A commentary on `Exercise and Depression': And the verdict is..... Mental Health and Physical Activity, 2, 97-99. http://dx.doi.org/10.1016/j.mhpa.2009.08.001

*Bonnet LH. (2005). Effects of aerobic exercise in combination with cognitive therapy on self reported depression. Dissertation. Hofstra University.

Bouchard, C., Sarzynski, M. A., Rice, T. K., Kraus, W. E., Church, T. S., Sung, Y. J. et al. (2011). Genomic predictors of the maximal O uptake response to standardized exercise 
training programs. J Appl.Physiol, 110, 1160-1170.

http://dx.doi.org/10.1152/japplphysiol.00973.2010

Bravata D.M., Smith-Spangler, C.F., Sundaram, V.F., Gienger A.L., Lin, N.F., Lewis, R.F., Stave C.D., Olkin, I.F., \& Sirard, J.R. (2007). Using pedometers to increase physical activity and improve health: a systematic review. JAMA, 298 (19) 2296-2304 http://dx.doi.org/10.1001/jama.298.19.2296

Brosse, A. L., Sheets, E. S., Lett, H. S., \& Blumenthal, J. A. (2002). Exercise and the Treatment of Clinical Depression in Adults: Recent Findings and Future Directions. Sports Medicine, 32, 741-760.

http://dx.doi.org/10.2165/00007256-200232120-00001

Centers for Disease Control and Prevention (2011). Kids Walk to School. http://www.cdc.gov/nccdphp/dnpa/kidswalk/ [Last accessed 24/05/2011].

Cipriani, A., Furukawa, T. A., Salanti, G., Geddes, J. R., Higgins, J. P., Churchill, R. et al. (2009). Comparative efficacy and acceptability of 12 new-generation antidepressants: a multiple-treatments meta-analysis. The Lancet, 373, 746-758. http://dx.doi.org/10.1016/S0140-6736(09)60046-5

Clark, L. A. \& Watson, D. (1991). Tripartite model of anxiety and depression: psychometric evidence and taxonomic implications. J Abnorm.Psychol., 100, 316-336. http://dx.doi.org/10.1037/0021-843X.100.3.316

Craft, L. L. \& Perna, F. M. (2004). The Benefits of Exercise for the Clinically Depressed. Prim.Care Companion.J Clin.Psychiatry., 6, 104-111. http://dx.doi.org/10.4088/PCC.v06n0301

Daley, A. (2008). Exercise and Depression: a Review of Reviews. Journal of Clinical Psychology in Medical Settings, 15, 140-147. http://dx.doi.org/10.1007/s10880-008-9105-z 
Demyttenaere, K. (2003). Risk factors and predictors of compliance in depression. European Neuropsychopharmacology, 13, 69-75. http://dx.doi.org/10.1016/S0924-977X(03)00095-6

de Wit, L. M., van, S. A., van, H. M., Penninx, B. W., \& Cuijpers, P. (2009). Depression and body mass index, a u-shaped association. BMC Public Health, 9, 14. http://dx.doi.org/10.1186/1471-2458-9-14

Faulkner, G. \& Carless, D. (2006). Physical activity in the process of psychiatric rehabilitation: theoretical and methodological issues. Psychiatr.Rehabil.J, 29, 258-266. http://dx.doi.org/10.2975/29.2006.258.266

Givens, J. L., Datto, C. J., Ruckdeschel, K., Knott, K., Zubritsky, C., Oslin, D. W. et al. (2006). Older Patients' Aversion to Antidepressants. J Gen Intern Med, 21, 146-151. http://dx.doi.org/10.1111/j.1525-1497.2005.00296.x

*Gusi, N., Reyes, M. C., Gonzalez-Guerrero, J. L., Herrera, E., \& Garcia, J. M. (2008). Costutility of a walking programme for moderately depressed, obese, or overweight elderly women in primary care: a randomised controlled trial. BMC Public Health.vol.8, 88, 231. http://dx.doi.org/10.1186/1471-2458-8-231

Hartig T, Mang M, Evans GW. (1991). Restorative effects of natural environment experiences. Environment and Behaviour, 23(1):3. http://dx.doi.org/10.1177/0013916591231001

Health Canada (2011). Physical Activity. http://www.hc-sc.gc.ca/hl-vs/physactiv/index-eng.php [Last accessed 24/05/11].

Heesch, K. C., Burton, N. W., \& Brown, W. J. (2011). Concurrent and prospective associations between physical activity, walking and mental health in older women. $\mathbf{J}$ Epidemiol.Community Health, 65, 807-813. http://dx.doi.org/10.1136/jech.2009.103077

Hotopf, M., Lewis, G., \& Normand, C. (1997). Putting trials on trial--the costs and consequences of small trials in depression: a systematic review of methodology. J Epidemiol 
Community Health, 51, 354-358.

http://dx.doi.org/10.1136/jech.51.4.354

International Longevity Center-USA (2011). Walk to a Healthy future.

http://www.ilcusa.org/media/pdfs/walkingib.pdf [Last accessed 24/05/11].

Kaplan R, Kaplan S. (1989). The experience of nature: A psychological perspective. Cambridge: Cambridge University Press.

Kessing, L. V., Vibe Hansen, H. A. N. N., Demyttenaere, K. O. E. N., \& Bech, P. E. R. (2005). Depressive and bipolar disorders: patients' attitudes and beliefs towards depression and antidepressants. Psychological Medicine, 35, 1205-1213. http://dx.doi.org/10.1017/S0033291705004605

King, A. C., Taylor, C. B., \& Haskell, W. L. (1993). Effects of differing intensities and formats of 12 months of exercise training on psychological outcomes in older adults. Health Psychol., 12, 292-300.

http://dx.doi.org/10.1037/0278-6133.12.4.292

Kirsch, I., Deacon, B. J., Huedo-Medina, T. B., Scoboria, A., Moore, T. J., \& Johnson, B. T. (2008). Initial Severity and Antidepressant Benefits: A Meta-Analysis of Data Submitted to the Food and Drug Administration. PLoS Med, 5, e45.

http://dx.doi.org/10.1371/journal.pmed.0050045

*Knubben, K., Reischies, F. M., Adli, M., Schlattmann, P., Bauer, M., \& Dimeo, F. (2007). A randomised, controlled study on the effects of a short-term endurance training programme in patients with major depression. British Journal of Sports Medicine. Vol.41, 411, 29-33.

Krogh, J., Nordentoft, M., Sterne, J. A., \& Lawlor, D. A. (2011). The effect of exercise in clinically depressed adults: systematic review and meta-analysis of randomized controlled trials. J Clin. Psychiatry, 72 (4):529-538.

http://dx.doi.org/10.4088/JCP.08r04913blu

Lawlor, D. A. \& Hopker, S. W. (2001). The effectiveness of exercise as an intervention in the management of depression: systematic review and meta-regression analysis of 
randomised controlled trials. BMJ, 322, 763.

http://dx.doi.org/10.1136/bmj.322.7289.763

Lowther, M., Mutrie, N., \& Scott, E.M. (2002). Promoting physical activity in a socially and economically deprived community: a 12 month randomized control trial of fitness assessment and exercise consultation. Journal of Sports Sciences, 20, (7) 577-588 available from: http://www.tandfonline.com/doi/abs/10.1080/026404102760000071 http://dx.doi.org/10.1080/026404102760000071

Maxwell, M. (2005). Women's and doctors' accounts of their experiences of depression in primary care: the influence of social and moral reasoning on patients' and doctors' decisions. Chronic Illness, 1, 61-71. http://dx.doi.org/10.1177/17423953050010010401

*McNeil, J. K., LeBlanc, E. M., \& Joyner, M. (1991). The effect of exercise on depressive symptoms in the moderately depressed elderly. Psychology and Aging, 6, 487-488. http://dx.doi.org/10.1037/0882-7974.6.3.487

Mead, G. E., Morley, W., Greig, C. A., McMurdo, M., \& Lawlor, D. A. (2008). Exercise for depression. Cochrane database of systematic reviews.

Mead, G. E., Morley, W., Campbell, P., Greig, C. A., McMurdo, M. E. T., \& Lawlor, D. A. (2009). Exercise for depression. Mental Health and Physical Activity, 2, 95-96. http://dx.doi.org/10.1016/j.mhpa.2009.06.001

Moncrieff, J. \& Kirsch, I. (2005). Efficacy of antidepressants in adults. British Medical Journal, $331,155-159$.

http://dx.doi.org/10.1136/bmj.331.7509.155

*Mota-Pereira, J., Silverio, J., Carvalho, S., Ribeiro, J. C., Fonte, D., \& Ramos, J. (2011). Moderate exercise improves depression parameters in treatment-resistant patients with major depressive disorder. Journal of Psychiatric Research, 45, 1005-1011. http://dx.doi.org/10.1016/j.jpsychires.2011.02.005 
Moussavi, S., Chatterji, S., Verdes, E., Tandon, A., Patel, V., \& Ustun, B. (2007). Depression, chronic diseases, and decrements in health: results from the World Health Surveys. The Lancet, 370, 851-858.

http://dx.doi.org/10.1016/S0140-6736(07)61415-9

Natural England (2011). Walking for Health. http://www.wfh.naturalengland.org.uk/ [Last accessed 24/05/2011].

*Nguyen, S. D. (2008). Simultaneous technique of exercise and psychotherapy (STEP) as an adjunct to multidisciplinary treatment in acute inpatient psychiatric hospitalized older adults with depressive symptoms. Dissertation. Loma Linda University.

NHS Choices Information (2011). The 10,000 Steps Challenge. http://www.nhs.uk/Livewell/loseweight/Pages/10000stepschallenge.aspx [Last accessed 24/05/2011]

NICE (2010). CG90 Depression in adults: full guidance.

http://guidance.nice.org.uk/CG90/Guidance/pdf/English [Last accessed 24/05/2011].

Ogilvie D, Foster C.E., Rothnie H, Cavill N, Hamilton V, Fitzsimons C.F. et al. (2007). Interventions to promote walking: systematic review. BMJ; 334(7605):1204. http://dx.doi.org/10.1136/bmj.39198.722720.BE

Orne, M. T. (1962). On the social psychology of the psychological experiment: With particular reference to demand characteristics and their implications. American Psychologist, 17, 776-783.

http://dx.doi.org/10.1037/h0043424

Ostler, K., Thompson, C., Kinmonth, A. L., Peveler, R. C., Stevens, L., \& Stevens, A. (2001). Influence of socio-economic deprivation on the prevalence and outcome of depression in primary care: the Hampshire Depression Project. The British Journal of Psychiatry, 178, $12-17$.

http://dx.doi.org/10.1192/bjp.178.1.12

Paths for All (2011). Paths for All. http://www.pathsforall.org.uk/ [Last accessed 24/05/2011]. 
Rethorst, C. D., Wipfli, B. M., \& Landers, D. M. (2009). The antidepressive effects of exercise: A meta-analysis of randomized trials. Sports Medicine.39(6)()(pp 491-511),

Review Manager (RevMan) [Computer program]. Version 5.1. (2011) Copenhagen: The Nordic Cochrane Centre, The Cochrane Collaboration.

Scottish Intercollegiate Guidelines Network. (2010) Non pharmaceutical management of depression in adults: a national cllinical guideline. http://www.sign.ac.uk/pdf/sign114.pdf (Accessed 24/05/2011).

Sjosten, N. \& Kivela, S. L. (2006). The effects of physical exercise on depressive symptoms among the aged: a systematic review. International Journal of Geriatric Psychiatry, 21, 410-418. http://dx.doi.org/10.1002/gps.1494

Smith, T. L., Masaki, K. H., Fong, K., Abbott, R. D., Ross, G. W., Petrovitch, H. et al. (2010). Effect of Walking Distance on 8-Year Incident Depressive Symptoms in Elderly Men with and without Chronic Disease: The Honolulu-Asia Aging Study. Journal of the American Geriatrics Society, 58, 1447-1452. http://dx.doi.org/10.1111/j.1532-5415.2010.02981.x

Sonstroem, R. J. \& Morgan, W. P. (1989). Exercise and self-esteem: rationale and model. Med Sci.Sports Exerc., 21, 329-337. http://dx.doi.org/10.1249/00005768-198906000-00018

Stathopoulou, G., Powers, M. B., Berry, A. C., Smits, J. A. J., \& Otto, M. W. (2006). Exercise interventions for mental health: A quantitative and qualitative review. Clinical Psychology-Science and Practice, 13, 179-193. http://dx.doi.org/10.1111/j.1468-2850.2006.00021.x

Suija, K., Pechter, U., Kalda, R., Tahepold, H., Maaroos, J., \& Maaroos, H. I. (2009). Physical activity of depressed patients and their motivation to exercise: Nordic Walking in family practice. Int J Rehabil.Res., 32, 132-138. http://dx.doi.org/10.1097/MRR.0b013e32831e44ef 
The Cochrane Collaboration (2011a). Cochrane Collaboration open learning material. http://www.cochrane-net.org/openlearning/html/mod13-4.htm [accessed 24/05/2011]. The Cochrane Collaboration (2011b). The Cochrane Handbook for Systematic Reviews of Interventions. Version 5.1.0, Part 2, Section 7.7.3.3. Higgins JP, Green S, editors. http://www.cochrane-handbook.org/.

The Cochrane Collaboration (2011c). The Cochrane Handbook for Systematic Reviews of Interventions. Version 5.1.0, Part 2, Section 12.6.2. Higgins JP, Green S, editors. http://www.cochrane-handbook.org/.

The Cochrane Collaboration (2011d). The Cochrane Handbook for Systematic Reviews of Interventions. Version 5.1.0, Part 2, Section 9.5.1. Higgins JP, Green S, editors. http://www.cochrane-handbook.org/.

The Countryside Agency (2005). Walking Ways to Health 2000-2005: Summary of Local Health Walk evaluations.

Thornicroft, G. \& Sartorius, N. (1993). The course and outcome of depression in different cultures: 10-year follow-up of the WHO Collaborative Study on the Assessment of Depressive Disorders. Psychological Medicine, 23, 1023-1032.

http://dx.doi.org/10.1017/S0033291700026489

Timmons, J. A., Knudsen, S., Rankinen, T., Koch, L. G., Sarzynski, M., Jensen, T. et al. (2010). Using molecular classification to predict gains in maximal aerobic capacity following endurance exercise training in humans. Journal of Applied Physiology, 108, 1487-1496. http://dx.doi.org/10.1152/japplphysiol.01295.2009

Townsend, A., Hunt, K., \& Wyke, S. (2003). Managing multiple morbidity in mid-life: a qualitative study of attitudes to drug use. BMJ, 327, 837. http://dx.doi.org/10.1136/bmj.327.7419.837

Ulrich RS. (1983) Aesthetic and affective responses to natural environment. In: Altman IWJF, editor. Human behaviour and environment: Vol 6. Behaviour and the natural environment. New York: Plenum. 
Ustun, T. B., Ayuso-Mateos, J. L., Chatterji, S., Mathers, C., \& Murray, C. J. L. (2004). Global burden of depressive disorders in the year 2000. The British Journal of Psychiatry, 184, 386-392.

http://dx.doi.org/10.1192/bjp.184.5.386

Welsh Assembly Government (2011). Walking and Cycling Action Plan 2009 - 2013. http://wales.gov.uk/topics/transport/publications/walkcycleactionplan09/?lang=en [Accessed 24/05/2011].

White, K., Kendrick, T., \& Yardley, L. (2009). Change in self-esteem, self-efficacy and the mood dimensions of depression as potential mediators of the physical activity and depression relationship: Exploring the temporal relation of change. Mental Health and Physical Activity, 2, 44-52.

http://dx.doi.org/10.1016/j.mhpa.2009.03.001

WHO (2003). Depression.

http://www.who.int/mental_health/management/depression/definition/en/ [Accessed 24/05/2011]

WHO (2010). The International Classification of Diseases 10th Revision.

http://apps.who.int/classifications/apps/icd/icd10online/ [accessed 31/01/2012]. 
Figure 1. Identification of eligible papers from systematic searches

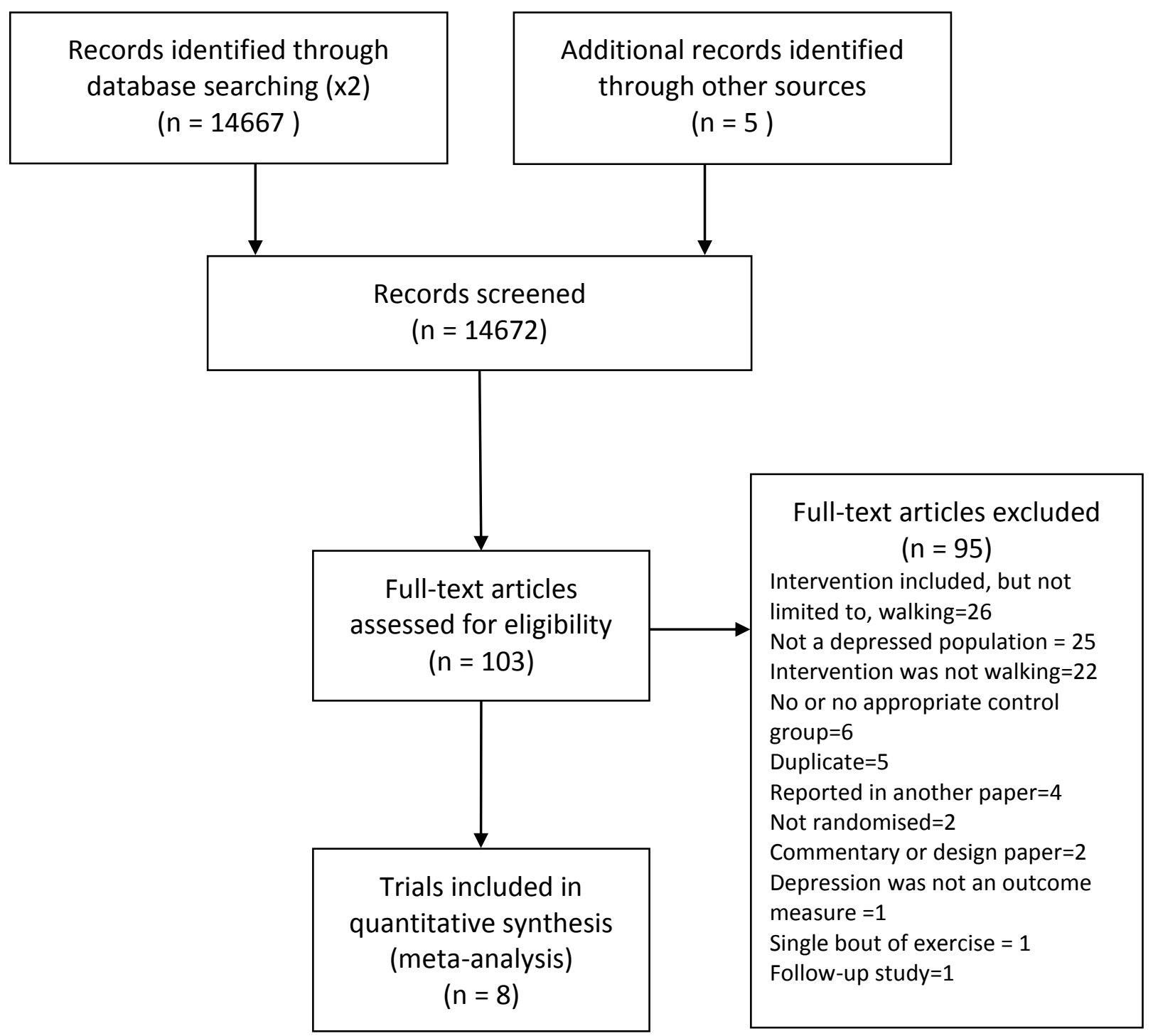

Where the study was excluded for several reasons, only one reason has been included in these figures. 
Figure 2. Meta-analysis of trials exploring the effects of walking as a treatment for depression

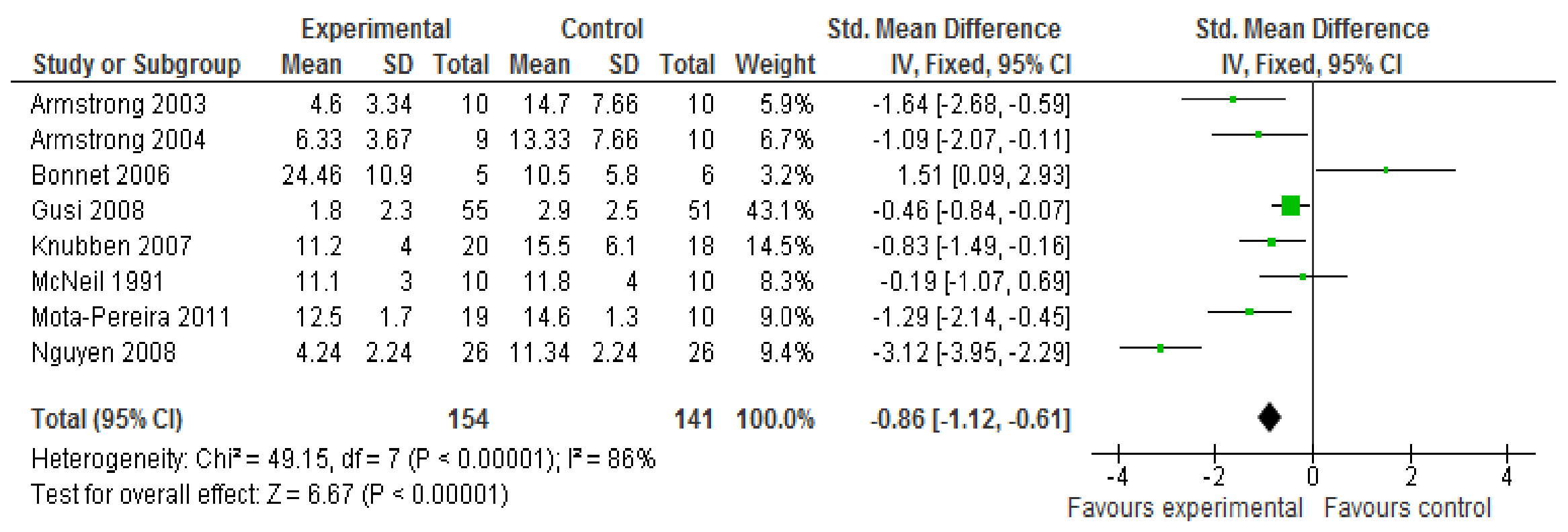


Table 1. Description of included trials

\begin{tabular}{|c|c|c|c|c|c|c|c|}
\hline $\begin{array}{l}\text { First author } \\
\text { and year of } \\
\text { publication }\end{array}$ & $\mathrm{N}$ & Country & Recruitment & Participants & $\begin{array}{l}\text { Intervention } \\
\text { (mins = minutes) }\end{array}$ & Control & $\begin{array}{l}\text { Quality } \\
\text { indicators } \\
\text { reported }^{a}\end{array}$ \\
\hline $\begin{array}{l}\text { Armstrong } \\
2003\end{array}$ & 20 & Australia & $\begin{array}{l}\text { Primary care, } \\
\text { secondary care and } \\
\text { community }\end{array}$ & $\begin{array}{l}\text { Women with child aged } 6 \text { weeks-12 } \\
\text { months; Edinburgh Postnatal } \\
\text { Depression Scale score }>11\end{array}$ & $\begin{array}{l}12 \text { weeks of outdoor pram walking, } 30-40 \\
\text { minutes, } 3 \times \text { weekly, in group, at moderate } \\
\text { intensity ( } 60-75 \% \text { of age predicted heart rate); } \\
\text { muscle stretching was carried out before and } \\
\text { after walks. After one walk each week an } \\
\text { informal gathering was held. }\end{array}$ & $\begin{array}{l}\text { No treatment/usual care } \\
\text { (apart from a phone call at } \\
\text { week 6). Advice to maintain } \\
\text { usual routine and social } \\
\text { activities. }\end{array}$ & $\mathrm{A}, \mathrm{I}, \mathrm{S}$ \\
\hline $\begin{array}{l}\text { Armstrong } \\
2004\end{array}$ & 24 & Australia & $\begin{array}{l}\text { Primary care and } \\
\text { community }\end{array}$ & $\begin{array}{l}\text { English speaking; have a child aged } 6 \\
\text { weeks - } 18 \text { months; Edinburgh } \\
\text { Postnatal Depression Scale score } \\
>11\end{array}$ & $\begin{array}{l}12 \text { weeks of outdoor pram walking, } 30-40 \\
\text { minutes, led } 2 x \text { weekly; encouraged to } \\
\text { undertake 3rd session in week independently. }\end{array}$ & Support group once/week & $A, S$ \\
\hline Bonnet 2005 & 11 & USA & $\begin{array}{l}\text { Student counseling } \\
\text { services; } \\
\text { Undergraduate } \\
\text { psychology class }\end{array}$ & $\begin{array}{l}\text { Meet DSM IV for major depressive } \\
\text { disorder, dysthymia or depressive } \\
\text { disorder; no regular physical activity } \\
\text { for } 3 \text { months, no antidepressants for } \\
12 \text { months }\end{array}$ & $\begin{array}{l}6 \text { weeks of cognitive therapy plus indoor } \\
\text { exercise (walking on treadmill, } 25-30 \text { minutes, } \\
\text { moderate intensity, } 2 x \text { week) }\end{array}$ & Cognitive therapy only & I \\
\hline Gusi 2008 & 127 & Spain & $\begin{array}{l}4 \text { general practices } \\
\text { recruited patients in a } \\
2 \text { week period. }\end{array}$ & $\begin{array}{l}\text { Elderly females aged } 60+\text {, overweight } \\
\text { (BMI } 25-39.9) \text { or moderately } \\
\text { depressed }(6-9 \text { points on geriatric } \\
\text { depression scale) ; able to walk for } \\
\text { over } 25 \text { minutes }\end{array}$ & $\begin{array}{l}6 \text { months of supervised group walks in a park } \\
\text { or on forest tracks. } 50 \text { minutes, three times } \\
\text { per week. Periods of walking were } \\
\text { interspersed with exercise (joint mobility, } \\
\text { strengthening, stretching and additional } \\
\text { mechanical impact). Simple nutritional advice } \\
\text { was provided. }\end{array}$ & Routine care & $\mathrm{A}, \mathrm{S}$ \\
\hline Knubben 2007 & 38 & Germany & $\begin{array}{l}\text { Consecutive series of } \\
\text { university hospital in- } \\
\text { patients. }\end{array}$ & $\begin{array}{l}\text { 20-70 years, German speaking, able } \\
\text { to walk. Diagnosed with a major } \\
\text { depressive episode according to } \\
\text { DSM-IV. Inclusion criteria included } \\
\text { scores }>12 \text { on the Bech-Rafaelsen } \\
\text { Melancholy Scale (BRMS). }\end{array}$ & $\begin{array}{l}10 \text { days } \times 30 \text { minutes daily of walking on a } \\
\text { treadmill using an interval training pattern at } \\
80 \% \text { ( } 220 \text {-age) heart rate } 50 \% \text { of the time and } \\
\text { at half speed the remaining time. }\end{array}$ & $\begin{array}{l}10 \text { days } \times 30 \text { mins daily light } \\
\text { stretching and relaxation } \\
\text { exercises }\end{array}$ & $\mathrm{A}, \mathrm{I}, \mathrm{S}, \mathrm{B}$ \\
\hline McNeil 1991 & 30 & Canada & $\begin{array}{l}\text { Community and } \\
\text { religious groups were } \\
\text { invited to refer } \\
\text { potential participants. }\end{array}$ & $\begin{array}{l}\text { Elderly (mean=72.5 years), } \\
\text { depressed (BDI score 12-24), no } \\
\text { cognitive impairment or treatment for } \\
\text { emotional problems }\end{array}$ & $\begin{array}{l}6 \text { weeks of walking (outside or in shopping } \\
\text { mall), } 20-40 \text { mins, } 2 x \text { week accompanied by } \\
\text { researcher and } 1 x \text { alone, }\end{array}$ & $\begin{array}{l}\text { Social contact control } \\
\text { condition }=2 x \text { week home } \\
\text { visit by psychology student, } \\
\text { casual conversation for } \\
\text { similar time to exercise } \\
\text { group. }\end{array}$ & 1 \\
\hline $\begin{array}{l}\text { Mota-Pereira } \\
2011\end{array}$ & 33 & Portugal & $\begin{array}{l}\text { Psychiatric } \\
\text { outpatients }\end{array}$ & $\begin{array}{l}\text { Treatment resistant major depressive } \\
\text { disorder for } 9 \text { to } 15 \text { months }\end{array}$ & $\begin{array}{l}\text { Home based } 30-45 \text { minutes/day walks, } 5 \\
\text { days/week, for } 12 \text { weeks. One walk each }\end{array}$ & $\begin{array}{l}\text { Usual care plus one visit to } \\
\text { research team each week to }\end{array}$ & $B$ \\
\hline
\end{tabular}




\begin{tabular}{|c|c|c|c|c|c|c|c|}
\hline $\begin{array}{l}\text { First author } \\
\text { and year of } \\
\text { publication }\end{array}$ & $\mathbf{N}$ & Country & Recruitment & Participants & $\begin{array}{l}\text { Intervention } \\
\text { (mins = minutes) }\end{array}$ & Control & $\begin{array}{l}\text { Quality } \\
\text { indicators } \\
\text { reporteda }^{2}\end{array}$ \\
\hline & & & & & week supervised. Wore accelerometer & $\begin{array}{l}\text { download accelerometer } \\
\text { data. }\end{array}$ & \\
\hline Nguyen 2008 & 58 & USA & $\begin{array}{l}\text { Psychiatric inpatients } \\
\text { interested in the trial }\end{array}$ & $\begin{array}{l}50 \text { years plus; psychiatric diagnosis } \\
\text { and with depressive symptoms; }<=24 \\
\text { on Mini-Mental Status Exam; }\end{array}$ & $\begin{array}{l}\text { While an inpatient (mean }=3.5 \text { sessions ) } \\
\text { indoor walk ( } 30 \text { minutes walking and talking } \\
\text { (validation psychotherapy)) with } 5 \text { minute } \\
\text { warm up. }\end{array}$ & Talking (psychotherapy) only. & $\mathrm{S}$ \\
\hline
\end{tabular}


Table 2. Description of how diagnoses of depression were made and outcome measures used in our meta-analysis

\begin{tabular}{lll}
\hline Author and year & How trial authors diagnosed depression & Outcome measure used in meta-analysis \\
\hline Armstrong 2003 & Edinburgh Postnatal Depression Scale $>$ 11 & Edinburgh Postnatal Depression Scale \\
\hline Armstrong 2004 & Edinburgh Postnatal Depression Scale $>$ 11 & Edinburgh Postnatal Depression Scale \\
\hline Bonnet 2005 & $\begin{array}{l}\text { Criteria of the Diagnostic and Statistical Manual for Mental Disorders-IV and minimal scores for } \\
\text { depression on BDI-II and CES-D }\end{array}$ & Becks Depression Inventory \\
\hline Gusi 2008 & Geriatric Depression Scale $=6$-9 OR Body Mass Index = 25-39.9 & Geriatric Depression Scale \\
\hline Knubben 2007 & $\begin{array}{l}\text { Admission to a university hospital for treatment of a major depressive episode diagnosed } \\
\text { according to Diagnostic and Statistical Manual for Mental Disorders-IV }\end{array}$ & Bech-Rafaelsen Melancholy Scale \\
\hline McNeil 1991 & Becks Depression Inventory score 12-24 & Becks Depression Inventory \\
\hline Mota-Pereira 2011 & Clinical interview using Diagnostic and Statistical Manual for Mental Disorders-IV criteria & Hamilton Rating Scale for Depression - HAMD17 \\
\hline Nguyen 2008 & Clinical interview using Diagnostic and Statistical Manual for Mental Disorders-IV criteria & Geriatric Depression Scale \\
\hline
\end{tabular}


Table 3. Intervention characteristics

\begin{tabular}{lccccc}
\hline Author and year & $\begin{array}{c}\text { Outdoors } \\
\text { or } \\
\text { indoors }\end{array}$ & Supervised/led & $\begin{array}{c}\text { Group or } \\
\text { individual }\end{array}$ & $\begin{array}{c}\text { Some stretching } \\
\text { exercises } \\
\text { included }\end{array}$ & Specific intensity of exercise aimed for \\
\hline Armstrong 2003 & Outdoors & $\sqrt{ }$ & Group & $\sqrt{ }$ & $60-75 \%$ of age predicted heart rate \\
\hline Armstrong 2004 & Outdoors & $\sqrt{ }$ & Mixed & $\sqrt{ }$ & $60-75 \%$ of age predicted heart rate \\
\hline Bonnet 2005 & $\begin{array}{c}\text { Indoors } \\
\text { (treadmill) }\end{array}$ & $\sqrt{ }$ & Individual & & $50 \%$ of heart rate reserve ( 4mph) \\
\hline Gusi 2008 & Outdoors & $\sqrt{ }$ & Group & $\sqrt{ }$ & Brisk walking \\
\hline Knubben 2007 & $\begin{array}{c}\text { Indoors } \\
\text { (treadmill) }\end{array}$ & $\sqrt{ }$ & Individual & & $80 \%$ of age predicted heart rate \\
\hline McNeil 1991 & mixed & Mixed (2/3) & Individual & & Vigorous walking \\
\hline Mota-Pereira 2011 & mixed & Mixed (1/5) & Individual & & Moderate intensity ( $(5 \mathrm{kph})$ \\
\hline Nguyen 2008 & indoors & $\sqrt{ }$ & Individual & $\sqrt{ }$ & - \\
\hline
\end{tabular}


Table 4. Pedometer and accelerometer use, motivational approaches and intervention completion rates

\begin{tabular}{lclc}
$\begin{array}{c}\text { Author and } \\
\text { year }\end{array}$ & $\begin{array}{c}\text { Pedometers or } \\
\text { accelerometers }\end{array}$ & \multicolumn{1}{c}{ Other promotional methods } & $\begin{array}{c}\text { Intervention completion rates } \\
(\%)\end{array}$ \\
\hline Armstrong 2003 & No & $\begin{array}{l}\text { Child care provided for initial meeting, group walking, researcher present, exercise profile diary kept by } \\
\text { participants where they recorded their heart rate; attendance register kept. }\end{array}$ & 100 \\
\hline Armstrong 2004 & No & Group walking (2 out of 3 walks/week), researcher present, heart rate checked during walks; & 75 \\
\hline Bonnet 2005 & No & None reported & 100 \\
\hline Gusi 2008 & No & Guided group walks & 86 \\
\hline Knubben 2007 & No & Hospital inpatient & 95 \\
\hline McNeil 1991 & No & Guided walks (2/3) & 100 \\
\hline Mota-Pereira & Accelerometer & $\begin{array}{l}\text { Diary, behavioural techniques such as leaving exercise shoes at door entrance, note on main door to } \\
\text { remind them to walk, cell phone reminders with specific ring tone, families asked to be involved, } 1 / 5\end{array}$ \\
2011 & & weekly walks supervised. & 94 \\
\hline Nguyen 2008 & Hospital inpatient & 90 \\
\hline
\end{tabular}


Table 5. Effect size and fitness level changes

\begin{tabular}{|c|c|c|c|c|c|}
\hline $\begin{array}{l}\text { First author and } \\
\text { year of publication }\end{array}$ & $\begin{array}{c}\text { Significant effect } \\
\text { size (See Figure 2) }\end{array}$ & $\begin{array}{l}\text { Fitness } \\
\text { measure } \\
\text { used }\end{array}$ & $\begin{array}{l}\text { Significant improvement in } \\
\text { fitness in intervention } \\
\text { group }\end{array}$ & $\begin{array}{l}\text { Significant improvement } \\
\text { in fitness in control } \\
\text { group }\end{array}$ & $\begin{array}{l}\text { Significant improvement in fitness } \\
\text { in intervention group compared to } \\
\text { control group }\end{array}$ \\
\hline Armstrong 2003 & Yes & $\mathrm{VO}_{2} \max$ & Yes & No & - \\
\hline Armstrong 2004 & Yes & $\mathrm{VO}_{2} \max$ & Yes & No & - \\
\hline Bonnet 2005 & No & $\begin{array}{l}\text { Resting heart } \\
\text { rate }\end{array}$ & No & - & - \\
\hline Gusi 2008 & Yes & - & - & - & - \\
\hline Knubben 2007 & Yes & $\mathrm{VO}_{2} \max$ & No & - & - \\
\hline McNeil 1991 & No & Cooper Test & Yes & No & Yes \\
\hline Mota-Pereira 2011 & Yes & Heart rate & - & - & No \\
\hline Nguyen 2008 & Yes & - & - & - & - \\
\hline
\end{tabular}

maximal oxygen uptake 